\title{
PRIMARY ENDOLEAKAGE IN ENDOVASCULAR TREATMENT OF THE THORACIC AORTA: IMPORTANCE OF INTRAOPERATIVE TRANSESOPHAGEAL ECHOCARDIOGRAPHY
}

Rossella Fattori, MD

Ilaria Caldarera, $\mathrm{MD}, \mathrm{PhD}^{\mathrm{b}}$

Claudio Rapezzi, $\mathrm{MD}^{\mathrm{c}}$

Guido Rocchi, MD

Gabriella Napoli, MDa

Mario Parlapiano, $\mathrm{MD}^{\mathrm{b}}$

Marco Favali, MD

Angelo Pierangeli, $\mathrm{MD}^{\mathrm{b}}$

Giampaolo Gavelli, MD
Objectives: Endovascular treatment of the thoracic aorta has developed as an efficacious alternative to open surgical repair. However, despite the high primary success rate, perigraft leakage constitutes the major concern in longterm follow-up. Endoleaks are widely reported both in abdominal and thoracic endovascular series and are usually identified by intraoperative angiography. Transesophageal echocardiography is a sensitive imaging technique in the evaluation of aortic diseases, widely used to monitor cardiac surgery. The aim of this study was to evaluate the efficacy of transesophageal echocardiography in leakage detection during endovascular stent procedures of the thoracic aorta.

Methods: Intraoperative transesophageal echocardiography was used in conjunction with angiography in 25 patients subjected to endovascular stent treatment of the descending thoracic aorta. Spiral computed tomographic scanning was performed before discharge and 3, 6, and 12 months after treatment.

Results: Information from transesophageal echocardiography was relevant in the selection of the landing zone in $62 \%$ of cases. In 8 patients, transesophageal echocardiography with color Doppler sonography showed a perigraft leak, 6 of which were not visible on angiography, suggesting the need for further balloon expansion or graft extension. Postoperative computed tomographic scanning in the 25 patients showed 1 endoleak, which sealed spontaneously. At 3 months, computed tomographic examination confirmed the absence of perigraft leakage in all patients.

Conclusions: During implantation of a stent-graft in the descending thoracic aorta, transesophageal echocardiography provides information in addition to that provided by angiography, improving immediate and late procedural results. (J Thorac Cardiovasc Surg 2000;120:490-5)
$E^{n}$ ndoluminal treatment of abdominal and thoracic aneurysms is emerging as reliable alternative to conventional surgical repair. Since the first application in 1991, this minimally invasive technique has been adopted by many vascular centers throughout the world.

From the Departments of Radiology, ${ }^{\mathrm{a}}$ Cardiovascular Surgery, ${ }^{\mathrm{b}}$ and Cardiology, ${ }^{\mathrm{c}}$ University of Bologna, Bologna, Italy.

Received for publication Jan 26, 2000; revisions requested March 31, 2000; revisions received May 15, 2000; accepted for publication May 25, 2000.

Address for reprints: Rossella Fattori, MD, Radiologia III, University Hospital "S. Orsola," Via Massarenti 9, 40138 Bologna, Italy (E-mail: ross@ med.unibo.it).

Copyright () 2000 by The American Association for Thoracic Surgery

$0022-5223 / 2000 \$ 12.00+0 \quad \mathbf{1 2 / 1 / 1 0 8 9 0 4}$

doi: $10.1067 / \mathrm{mtc} .2000 .108904$
Particularly in thoracic aortic diseases, endovascular stent treatment demonstrated lower mortality and morbidity than open transthoracic surgical repair, offering a therapeutic option even to patients who would not otherwise be considered candidates for surgery. ${ }^{1}$ However, despite the high primary success rate, endoleaks are frequently reported in both abdominal and thoracic series after successful endovascular repair, constituting the main cause of late treatment failure. ${ }^{2-4}$

Endoluminal stent-graft placement is usually performed in the operating room under fluoroscopic and angiographic guidance. Angiography is commonly used as the imaging method to select the optimal landing zone or to confirm aneurysm exclusion after stent deployment. We report the usefulness of intraoperative transesophageal echocardiography (TEE) in compari- 
Table I. Aortic lesions characteristics

\begin{tabular}{lccccc}
\hline Etiology & $\begin{array}{c}\text { No. of } \\
\text { patients }\end{array}$ & Age $(y)$ & $\begin{array}{c}\text { Aneurysm diameter } \\
(\mathrm{mm})\end{array}$ & $\begin{array}{c}\text { Proximal neck } \\
(\mathrm{mm})\end{array}$ & $\begin{array}{c}\text { Distal neck } \\
(\mathrm{mm})\end{array}$ \\
\hline Dissection & 7 & $66 \pm 2$ & $51 \pm 7.5$ & $35.3 \pm 2.7$ & $32.8 \pm 2.2$ \\
Atherosclerosis & 8 & $69 \pm 8.7$ & $58.6 \pm 8.4$ & $35.8 \pm 2.7$ & $150 \pm 32$ \\
Trauma & 7 & $42 \pm 11$ & $37.5 \pm 5.5$ & $24.6 \pm 2.8$ & $24 \pm 3.7$ \\
Penetrating ulcer & 3 & $64.6 \pm 6$ & $56 \pm 5.6$ & $31 \pm 6$ & $34 \pm 10$ \\
\hline
\end{tabular}

son with angiography in detecting leakage after stent deployment and its efficacy in optimizing the procedural results.

\section{Methods}

Patients. From July 1997 to October 1999, 25 patients affected by various thoracic aortic diseases underwent endoluminal stent-graft repair (Table I). The group comprised 22 men and 3 women. The mean age was $60.8 \pm 12.9$ (28-80 years), and the American Surgical Association class was I-II in 6 , III-IV in 15 , and $\mathrm{V}$ in the remaining 4. Endovascular stent-grafts were implanted in the operating room with the patients under general anesthesia and invasive monitoring of right-sided arterial pressure with a double-lumen central venous catheter. Each stent-graft prosthesis (Talent TM, World Medical Manufacturing Corporation, Sunrise, Fla) was individually manufactured on the basis of magnetic resonance imaging (spin-echo, multiplane acquisition, and magnetic resonance angiography) or spiral computed tomographic (CT) measurement with 2-dimensional and 3-dimensional reconstruction. All procedures were monitored by a portable digital radiographic C-arm image intensifier with digital subtraction angiography (Angiovis, Burgatti Spa, Bologna, Italy) and by TEE (Hewlett-Packard Sonos 2000 sonograph; HewlettPackard Company, Palo Alto, Calif) with a multiplane transesophageal probe. At the beginning of the procedure, an aortogram was performed by a pigtail catheter inserted in the left brachial artery. TEE evaluation of the thoracic aorta was then applied to visualize the aortic disease, as well as eventual aortic plaque, mural thrombus, or calcification along the aortic wall, with the purpose to avoid stent deployment in unfavorable aortic segments. The endovascular stent system was inserted over the guide wire by surgical exposure of the femoral or iliac artery and advanced on fluoroscopic and TEE guidance. In all cases a distance of at least $1 \mathrm{~cm}$ from the left subclavian artery and from the celiac artery was observed, to guarantee adequate sealing at the neck sites. After identification of the most favorable landing zone, according to the aortic wall condition visualized by TEE and previous computed tomographic/magnetic resonance imaging (CT/MRI) data, stent deployment was monitored by fluoroscopy with the TEE probe used as a marker facing the selected area. Subsequent balloon inflations were then performed in proximal and distal necks to mold the prosthesis on the aortic wall. After stent deployment, TEE with color Doppler sonography was used to visualize the absence of flow in the perigraft zone. An initial "smoke" phenomenon, indicative of initial thrombosis within the aneurysm lumen, or in the false lumen in the case of dissection, was noticed as an indirect sign of aneurysm exclusion. The whole stent-graft length was carefully examined for sites of eventual periprosthetic leak.

When good results were confirmed both by angiographic and TEE studies, the placement system was removed and the arteriotomy was sutured.

Before discharge, all patients were subjected to spiral CT study of the thoracic aorta to confirm the correct stent-graft position and to exclude perigraft leak. Spiral CT was then repeated at 3,6 , and 12 months and yearly thereafter.

\section{Results}

Endovascular stent-graft treatment was successful and free of complication in all cases. Information derived from TEE was decisive in choosing the stentgraft landing zone in 16 patients $(62 \%)$. In 4 patients a mismatch between the stent-graft and the proximal aortic neck previously selected on the basis of CT measurements (aortic diameter bigger than stent diameter) was avoided by TEE measurement. In 12 cases TEE observations suggested that the proximal or distal landing zone be moved slightly due to severe aortic wall atherosclerosis not detected with angiography.

After the procedure a persistent proximal perigraft leak was diagnosed by TEE color Doppler sonography in 8 patients, whereas angiography visualized only 2 leaks. In 3 cases a further graft segment was necessary to eliminate proximal or distal perigraft leakage. In 4 patients several balloon expansions resulted in better graft adhesion to the aortic wall (Fig 1). In a patient with a fusiform post-traumatic aneurysm requiring 2 stent-grafts positioned in series with 20 -mm overlapping, a persistent leak was evident at color Doppler sonography in the hinge zone between the 2 stent-graft units. Successive balloon inflations provided a decrease of the flow velocity Doppler curves, but not a complete disappearance. Angiography did not show any leakage, and the stent system was removed. Spiral 

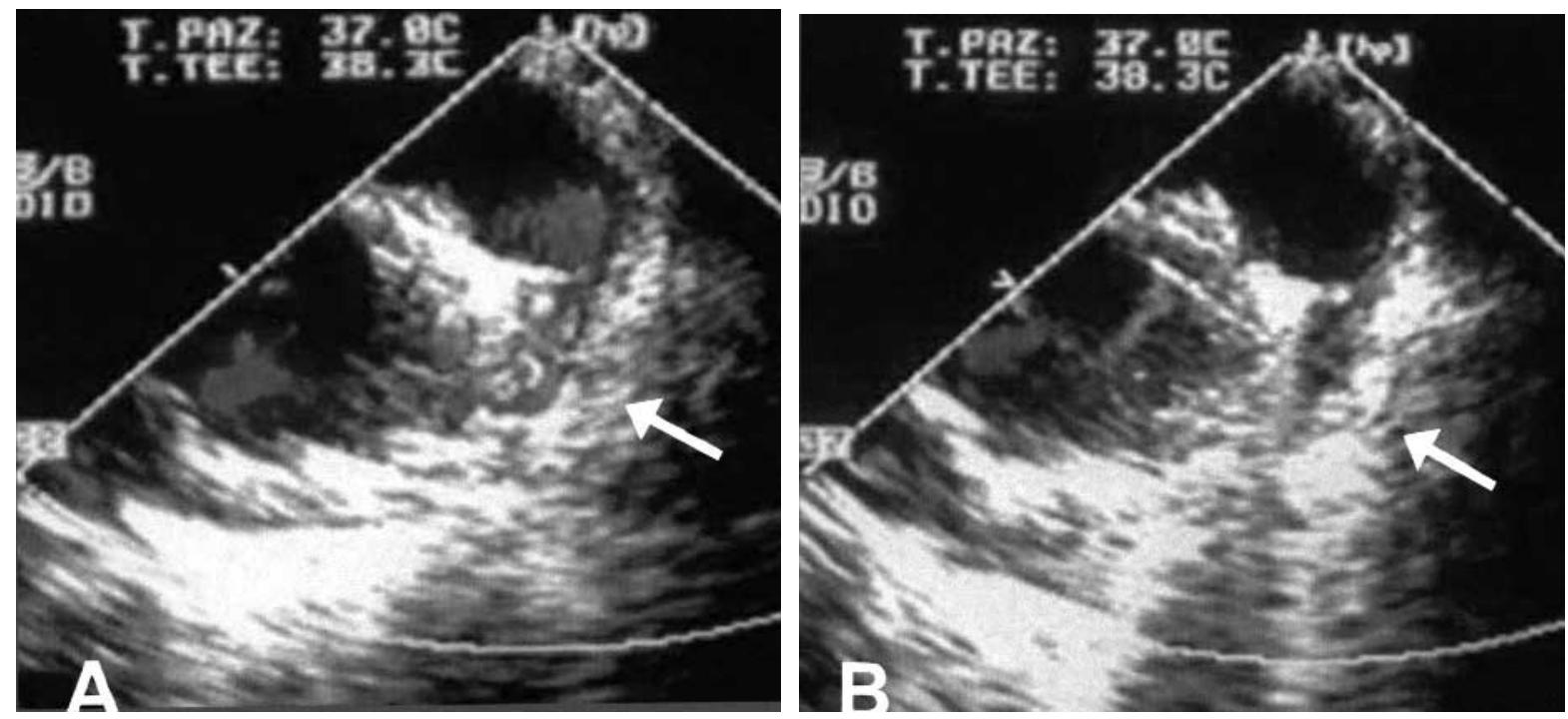

Fig 1. A, Perigraft leak detected by TEE color Doppler sonography (arrow). B, After balloon inflation, no flow is visible in the perigraft space.

CT scan performed on the seventh postoperative day demonstrated a type I perigraft leak in the junction between the 2 stent segments, in the absence of aneurysm expansion. At 3 months the follow-up CT scan showed spontaneous thrombosis and reduction in the size of the initial aneurysm (Fig 2).

In all the other cases, postoperative CT scans demonstrated correct graft positioning with no endoleak. Oneyear CT follow-up is available in the first 19 patients, and no secondary leakage has been observed.

\section{Discussion}

The natural history of thoracic aortic aneurysms is progressive expansion and rupture, with the 5-year actuarial survival being below $20 \%$ in patients treated medically. ${ }^{5,6}$ The traditional therapy for patients with aortic aneurysms is surgical repair. Nevertheless, despite advances in surgical techniques and anesthesiology, surgical treatment of the descending aorta carries the risk of high morbidity and mortality. In the largest surgical series, operative mortality ranges from $5 \%$ to $20 \%$ and postoperative renal and pulmonary insufficiency frequently result in prolonged hospital stay. Moreover, paraplegia continues to be a devastating complication associated with this type of operation..$^{7-9}$ Endovascular stent-graft treatment is a promising, nonsurgical therapy for diseases of the descending aorta and has rapidly evolved as a valuable alternative to conventional surgical repair. At present, the largest endovascular experience has been mostly in abdominal aneurysms, with more than 10,000 stent-graft implants throughout the world, whereas in thoracic aortic diseases the endovascular series are limited. ${ }^{10-13}$ Clinical trials on the use of different device systems in abdominal aortic aneurysms are progressing in many centers. However, despite a high technical success rate, postoperative perigraft leaks have been widely reported, occurring in as high as $44 \%$ of cases in some series. ${ }^{2}$ Endoleakage is defined as the persistence of blood flow outside the graft but within the aneurysmal sac occurring after endoluminal stent treatment. A high diastolic pressure persisting in the aneurysm sac may generate further aneurysm expansion and rupture. ${ }^{14}$ Large endoleaks usually originate from the proximal or distal end of the graft due to incomplete adhesion to the aortic wall (type I endoleak). Endoleaks may be associated with an open side branch (type II endoleak) or may arise at the junction between 2 graft segments. Endoleaks may become visible early after treatment (primary endoleak) or appear several months thereafter (secondary endoleak), probably related to dislodgment of the graft material or to structural changes of the aortic wall at the neck site. Aneurysm expansion in the absence of visible perigraft leak is also reported, ${ }^{15}$ carrying the hypothesis that endoleaks are not always visualized by current imaging methods, such as angiography or CT. In an experimental study, Schurink and coworkers ${ }^{16}$ demonstrated that if thrombi were present in the aneurysmal sac, small 

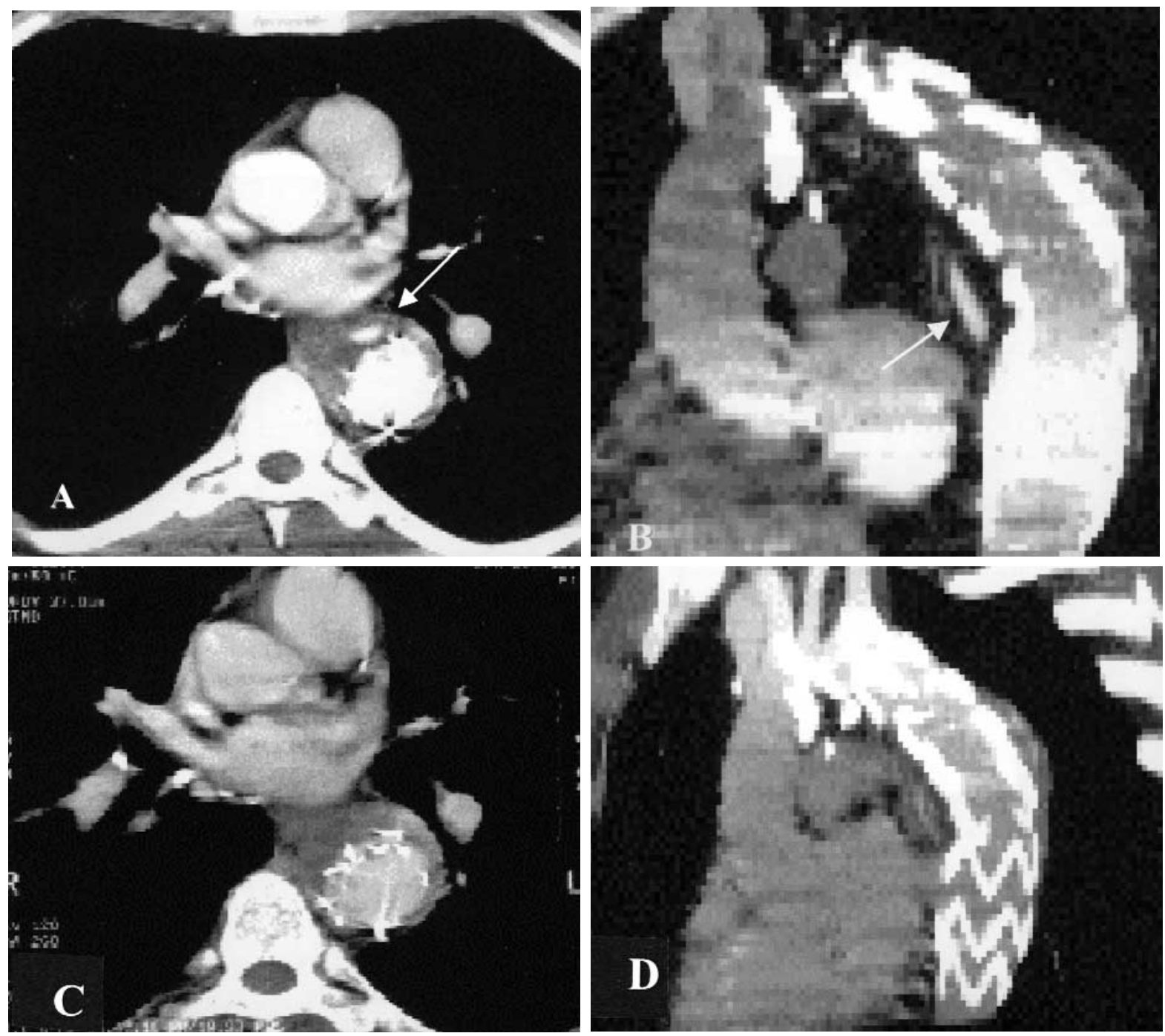

Fig 2. A and B, Spiral CT scans revealing an endoleak in a large fusiform post-traumatic aneurysm after stent treatment. C and D, Three-month follow-up scans showed a spontaneous thrombosis.

endoleaks were not visualized by digital subtraction angiography and $\mathrm{CT}$, although they were associated with high diastolic pressure in the perigraft space.

Stent-graft placement is guided by a portable C-arm $\mathrm{x}$-ray system capable of digital subtraction angiography and road mapping. Usually, the diagnosis of endoleak relies exclusively on this imaging method. At present, portable $\mathrm{x}$-ray systems have been implemented by high-resolution parameters of fluoroscopy and digital subtraction angiography, providing image characteristics apparently not different from fixed angiographic systems. However, image quality of conventional angiographic suites can be superior to those obtained by portable systems in the operating room.
In the past few years, the role of aortography in the diagnosis of aortic diseases has been debated because of continuous advances of the noninvasive imaging modalities. TEE is recognized as a sensitive diagnostic tool in the evaluation of various aortic diseases. ${ }^{17-19}$ Unlike angiography, TEE allows direct visualization and characterization of the aortic wall, such as simple aortic plaques or more complex lesions protruding into the lumen. ${ }^{20}$ The sensitivity of TEE color Doppler sonography in the detection of perigraft flow has been previously reported. In the evaluation of composite grafts of the ascending aorta, Barbetseas and coworkers ${ }^{21}$ showed 6 cases of perivalvular dehiscence identified by color Doppler sonography, 5 of them missed by angiography. Similarly, 

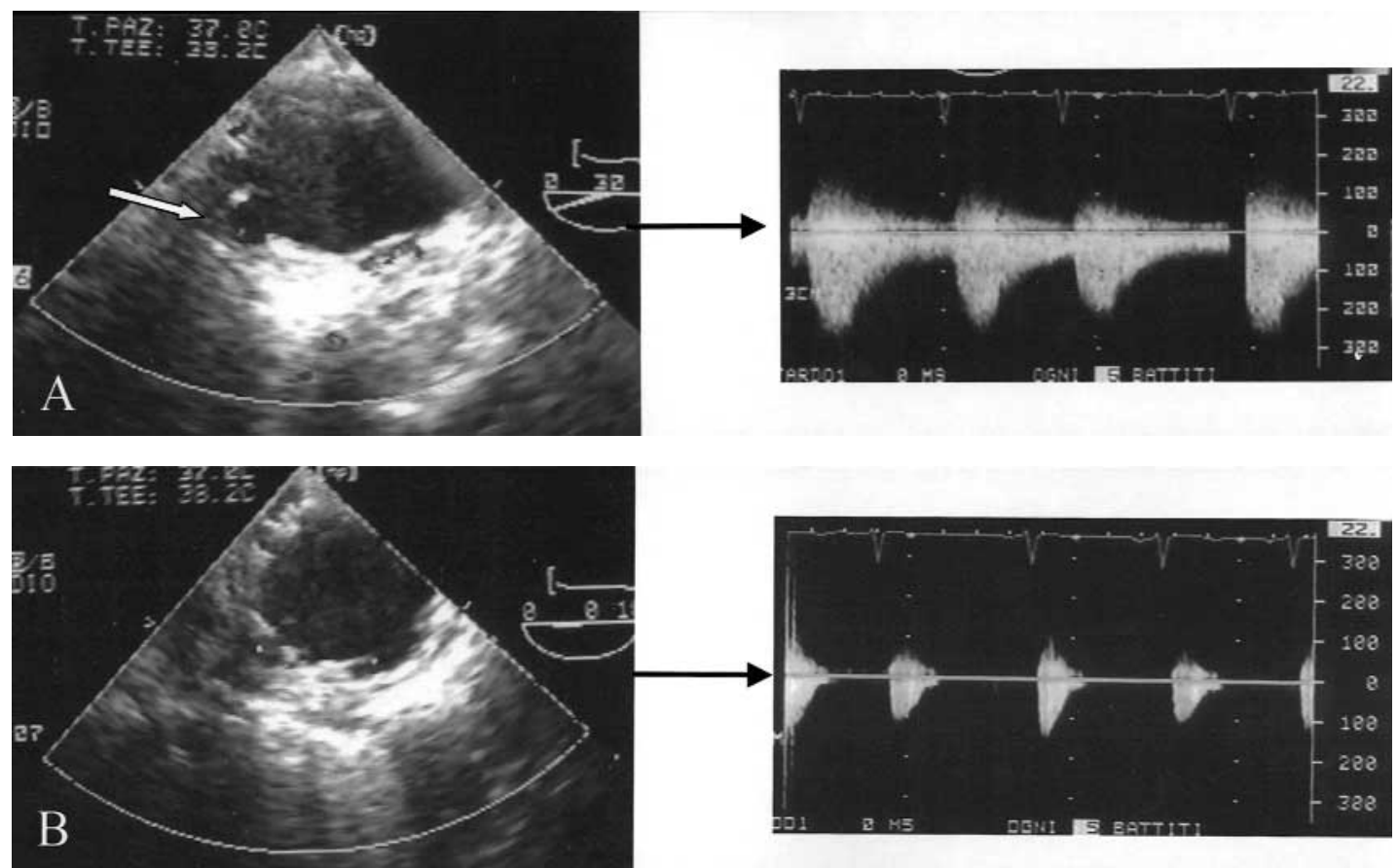

Fig 3. A, TEE color Doppler sonogram showing a perigraft leak immediately after stent deployment, with a high flow velocity. B, After successive balloon inflations, a slow flow velocity remains in the aneurysmal sac, indicative of minimal graft porosity.

in our series 6 cases of endoleak detected by TEE were not visible on intraoperative angiography. Flow dynamics can be accurately displayed by the support of color Doppler sonography. In the 8 cases of perigraft leaks that we observed, the flow curves were characterized by a high-velocity profile, different from the slow flow of Dacron graft porosity we occasionally observed immediately after deployment (Fig 3).

The only real proof of treatment efficacy of an aneurysm is its reduction in diameter during follow-up examinations. Unfortunately, shrinkage of the aneurysm sac takes several months after endovascular treatment, and in this interval an undetected endoleak remains at risk of rupture. The risk of aneurysm expansion in untreated leakage is particularly worrisome in the thoracic aorta. The Stanford group reported an average follow-up of 1.8 years in 103 patients, with endoleaks occurring in $24 \% .^{4}$ In our more limited series, we observed only 1 leak at postoperative CT scan: this was a case, early in our experience, in which we did not trust TEE, which was showing a small leak not visible on angiography.

The correct contact between the prosthesis and the aortic wall can be hampered by a significant wall atherosclerosis or calcification, resulting in perigraft leak or in secondary endoleaks over time. Otherwise these leaks, if promptly diagnosed, can be safely treated during the same procedure in which the stent-graft is molded on the aortic wall by successive balloon expansions or by adding a graft extension.

\section{Conclusion}

TEE is suitable for use throughout the procedure of stent-graft placement. In our consecutive series of patients with disease of the descending thoracic aorta, the contribution of TEE in conjunction with angiography was relevant to achieving the best procedural results. TEE made it possible to visualize the proximal aneurysm neck in all patients, identifying the optimal landing zone for dimensions and wall morphology, excluding significant atherosclerosis or calcifications. After stent-graft deployment, TEE with color Doppler sonography seems to be more sensitive than intraoperative angiography in identifying perigraft leaks.

\section{REFERENCES}

1. Dake MD, Miller DC, Semba CP, Mitchell RS, Walker PJ, Liddell RP. Transluminal placement of endovascular stent-grafts for the treatment of descending thoracic aortic aneurysm. N Engl J Med 1994;331:1729-34. 
2. White GH, Yu W, May J, Chaufur X, Stephens MS. Endoleak as a complication of endoluminal grafting of abdominal aortic aneurysms: classification, incidence, diagnosis and management. J Endovasc Surg 1997;4:152-68.

3. Golazarian J, Struyven J, Abada HT, Wery D, Dussaussois L, Madani A, et al. Endovascular aortic stent-grafts: transcatheter embolization of persistent perigraft leaks. Radiology 1997;202:731-4

4. Mitchell RS, Miller DC, Dake MD, Semba CP, Moore KA, Sakai T. Thoracic aortic aneurysm repair with an endovascular stent graft: the "first generation." Ann Thorac Surg 1999;67:1971-4.

5. Clouse WD, Hallett JW, Schaff HV, Gayari MM, Ilstrup DM, Melton LJ 3rd. Improved prognosis of thoracic aortic aneurysm: a population based study. JAMA 1998;9:280:1926-9.

6. Pressler V, McNamara JJ. Thoracic aortic aneurysm: natural history and treatment. J Thorac Cardiovasc Surg 1980;79:489-98.

7. Kouchoukos NT, Dougenis D. Surgery of the thoracic aorta. N Engl J Med 1997;336:1876-88.

8. Schor JS, Yerlioglu E, Galla JD, Lansman SL, Ergin MA, Griepp RB. Selective management of acute type B aortic dissection: long-term follow-up. Ann Thorac Surg 1996;61:1339-41.

9. Crawford ES, Crawford JL, Safi HJ, Coselli JS, Hess KR, Brooks $\mathrm{B}$, et al. Thoracoabdominal aortic aneurysms: preoperative and intraoperative factors determinating immediate and long term results of operations in 605 patients. J Vasc Surg 1986;3:389-404.

10. Kato N, Dake MD, Miller DC, Semba CP, Mitchell RS, Razavi MK, et al. Traumatic thoracic aortic aneurysm: treatment with endovascular stent. Radiology 1997;205:657-62.

11. Nienaber CA, Fattori R, Lund G, Dieckmann C, Wolf W, von Kodolitsch Y, et al. Nonsurgical reconstruction of thoracic aortic dissection by stent-graft placement. $\mathrm{N}$ Engl J Med 1999;340:1539-45.

12. Ehrlich M, Grabenwoeger M, Cartes-Zumelzu, Grimm M, Petzl D, Lammer J, et al. Endovascular stent graft repair for aneurysms on the descending thoracic aorta. Ann Thorac Surg 1998;66:19-25.
13. Dake MD, Kato N, Mitchell RS, Semba CP, Razavi MK, Shimono T, et al. Endovascular stent-graft placement for the treatment of acute aortic dissection. $\mathrm{N}$ Engl J Med 1999;340:1546-52.

14. Lumsden AB, Allen RC, Chaikof EL, Resnikoff M, Moritz MW, Gerhard H, et al. Delayed rupture of aortic aneurysms following endovascular stent grafting. Am J Surg 1995;170:174-8

15. Alimi YS, Chakfe N, Rivoal E, Slimane KK, Valerio N, Riepe G, et al. Rupture of an abdominal aortic aneurysm after endovascular graft placement and aneurysm size reduction. J Vasc Surg 1998;28:178-83.

16. Schurink GWH, Aarts NJM, Wilde J, van Baalen JM, Chuter TA, Schultze Kool LJ, et al. Endoleakage after stent-graft treatment of abdominal aneurysm: implications on pressure and imaging-an in vitro study. J Vasc Surg 1998;28:234-41.

17. Freeman WK. Diseases of aorta. In: Freeman WK, Seward JB, Khandheria BK, Tajik AJ, editors. Transesophageal echocardiography. Philadelphia: Little Brown; 1994.

18. Kyo S, Takamoto S, Omoto R, et al. Intraoperative echocardiography for diagnosis and treatment of aortic dissection. Hertz 1992;17:377-89.

19. Rizzo RJ, Aranki SF, Aklog L, Couper GS, Adams DH, Collins $\mathrm{JJ} \mathrm{Jr}$, et al. Rapid noninvasive diagnosis and surgical repair of acute ascending aortic dissection: improved survival with less angiography. J Thorac Cardiovasc Surg 1994;108:567-75.

20. Katz ES, Tunick PA, Rusinek H, Ribakove G, Spencer FC, Kronzon I. Protruding aortic atheromas predict stroke in elderly patients undergoing cardiopulmonary bypass: experience with intraoperative transesophageal echocardiography. J Am Coll Cardiol 1992;20:70-7.

21. Barbetseas J, Crawford ES, Safi HJ, Coselli JS, Quinones MA, Zoghbi WA. Doppler echocardiographic evaluation of pseudoaneurysms complicating composite grafts of the ascending aorta. Circulation 1992;85:212-22. 